\title{
REGULAR PERIODIC WAVES RUNUP AND OVERTOPPING SIMULATIONS BY LAGRANGIAN BLOCKS
}

\author{
Lai-Wai Tan ${ }^{1}$ and Vincent H. $\mathrm{Chu}^{2}$
}

\begin{abstract}
Wave runup and overtopping of truncated beaches have been simulated using the method of Lagrangian Block Hydrodynamics (LBH). Instead of interpolation, which causes numerical oscillations, the fluxes through the face of the finite-volume in the LBH method are determined by the advection of the blocks. Negative water depth is not possible and the computation is unconditionally stable as the momentum is updated by the re-construction of the blocks. The accuracy of the method is evaluated using (i) the exact solution of the collapsing bore and (ii) the available laboratory data of the solitary waves as the benchmarks. The numerical simulations carried out for regular periodic waves cover a wide range of wave steepness and beach slopes taking advantage of the inherent shockcapturing and shoreline-tracking capabilities of the LBH method.
\end{abstract}

Keywords: Lagrangian block hydrodynamics; regular periodic waves; wave runup; wave overtopping; shock capture; shoreline tracking

\section{INTRODUCTION}

Design of the coastal defense structures would depend on simulation if reliable numerical method could be employed to compute the wave impact on the structures. Structural porosity, roughness and other effects could be readily determined by numerical computations for optimal design of the structures. The numerical challenges have been in the capturing of the breaking-wave and the tracking of the moving shoreline where the water meets the dry land. Computations will collapse as a consequence of numerical instability when the depth of water becomes negative at the shoreline. The artificial numerical oscillations have to be managed for long-term computational stability in a simulation using the classical finite-volume method (Kobayashi \& Wurjanto 1989, Dodd 1998, Titov \& Synolakis 1995, Li \& Raichlen 2002, Lynett \& Liu 2002, Briganti \& Dodd 2009). Total control of the numerical oscillations is not generally feasible within the framework of the classical method.

In the Lagrangian Block Hydrodynamics (LBH) method developed by Tan \& Chu (2009a,b, 2010a-c), the mass and momentum are transferred by the Lagrangian advection of the blocks. The computational stability of the LBH method is absolute because the spurious numerical oscillations associated with the classical Eulerian method of the fluxes are avoided. The blocks capture depth and velocity discontinuities accurately. Negative water depth is not possible and the computation is unconditionally stable as the momentum is updated by the re-construction of the blocks. In this paper, the accuracy of the method is determined by the wave runup and overtopping problems that have either exact solutions or reliable experimental data. The first series of simulations were conducted for the collapsing bore. The results are compared with the exact solutions of Shen \& Meyer (1963) and Peregrine \& Williams (2001). The second series of simulations were carried out for runup of the solitary waves. The simulation results are verified by the available laboratory experimental data. Taking advantage of the shock-capturing and shoreline-tracking capabilities of the LBH method, the runup and overtopping simulations of the periodic waves are carried out as an application. The simulations of the periodic waves covered a wide range of wave steepness and beach slopes. The results are compared with the formulae for the regular waves that are recommended for the design of the coastal defense structures.

\section{LAGRANGIAN BLOCK HYDRODYNAMICS}

The Lagrangian blocks are arrays of contiguous fluid elements which are numerically constructed to satisfy the mass and momentum conservations. Figure 1(a) shows the Eulerian mesh and the nodes where the water depth $h(i, j)$, and the velocities $u(i, j)$ and $v(i, j)$ are defined. Figure 1(b) shows the advection of the volume block and Figures 1(c-d) show the advection of the momentum blocks. The mass and the momentum are carried by separate systems of the blocks. The numerical computation consists of two steps: (i) Lagrangian advection of the blocks and (ii) re-construction of the blocks as

\footnotetext{
${ }^{1}$ Lecturer, Faculty of Civil and Environmental Engineering, University Tun Hussein Onn, Malaysia

2 Professor, Department of Civil Engineering and Applied Mechanics, McGill University, 817 Sherbrooke Street West, Montreal, Quebec, H3A 2K6, Canada. E-mail: vincent.chu@mcgill.ca
} 
mass and momentum are re-distributed back onto the Eulerian mesh in every time increment. The reconstruction algorithm assumes advection of the block only to its neighboring cells. Therefore, the computational time step must not be too large to cause advection beyond its neighbors. A numerical solution is possible as long as the minimum of the two Courant numbers $\mathrm{Co}_{x}=u \Delta t / \Delta x$ and $\mathrm{Co}_{y}=v \Delta t / \Delta y$ is less than the value of unity.
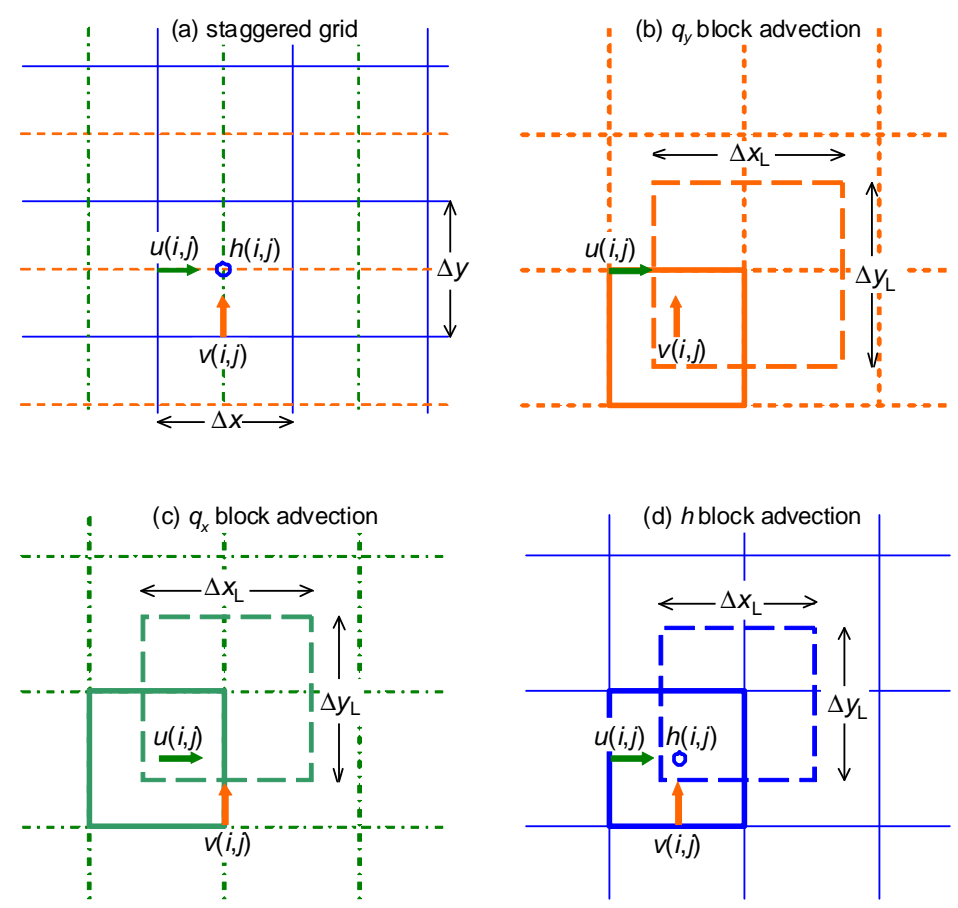

Figure 1. (a) The staggered grid showing the depth and velocity nodes, (b)-(d) block denoted by the solid rectangle at the beginning of the Lagrangian advection when time $=t$, and the block denoted by the dashed rectangle at the end of the advection time increment when time $=t+\Delta t$.

A block of fluid is defined by its depth $h_{\mathrm{L}}(i, j)$, and widths $x_{\mathrm{L}}(i, j-1)-x_{\mathrm{L}}(i, j)=\Delta x_{\mathrm{L}}$ and $y_{\mathrm{L}}(i, j)-$ $y_{\mathrm{L}}(i, j-1)=\Delta y_{\mathrm{L}}$. At the beginning of the computation time step $t$, the Lagrangian blocks fit the Eulerian mesh, that is $x_{\mathrm{L}}(i, j)=x(i, j)$ and $y_{\mathrm{L}}(i, j)=y(i, j)$. At the end of the time step $t+\Delta t$, for volume conservation: $\Delta x_{\mathrm{L}} \Delta y_{\mathrm{L}} h_{\mathrm{L}}(i, j)=\Delta x \Delta y h(i, j)$. In the present simulation, the forces on the blocks are calculated assuming hydrostatic pressure variation over the depth. The edge positions of the blocks $x_{\mathrm{L}}(i, j)$ and $y_{\mathrm{L}}(i, j)$ at time $t+\Delta t$ are calculated by integrating the momentum equations:

$$
\begin{aligned}
& \frac{d u_{i, j}}{d t}=-g \frac{h_{i, j}-h_{i-1, j}}{\Delta x}-g\left(S_{o x}-S_{f x}\right) \\
& \frac{d v_{i, j}}{d t}=-g \frac{h_{i, j}-h_{i-1, j}}{\Delta y}-g\left(S_{o y}-S_{f y}\right)
\end{aligned}
$$

where $\left(u_{i, j}, v_{i, j}\right)=\operatorname{velocity},\left(S_{o x}, S_{o y}\right)=$ bottom slope, $S_{f x}=c_{f} u_{i, j}\left|u_{i, j}\right| /\left(2 g h_{\text {avg }}\right)$ and $S_{f y}=c_{f} v_{i, j}\left|v_{i, j}\right| /\left(2 g h_{\text {avg }}\right)$ are $x$-component and $y$-component of the friction slope, respectively. To avoid entanglement of Lagrangian paths between adjacent blocks, the mass blocks are re-constructed at each time step. The mass and momentum are perfectly conserved through the process of re-distribution and the reconstruction of the blocks. The most significant advantage of this LBH method is its computational stability. The method ensures positive water depth and has not produced any numerical oscillation. 
LBH simulations have been conducted for various problems. Grid refinement studies were carried out for a number of problems by Tan \& Chu (2009a,b, 2010a-c) to show the convergence of the LBH simulations to the exact solutions. These include the dam-break waves on flat beds of Ritter (1892), Stoker (1957) \& Hogg (2006), the dam-break waves on a steep slope of Ancey et al. (2008), and the solution of Thacker (1981) for the wetting-and-drying of water in a parabolic bowl.

\section{COLLAPSING BORE - RUNUP}

The runup and overtopping simulations by LBH method are first carried out for the collapsing bore. The collapsing bore has an exact solution due to Shen \& Meyer (1963) and it has been widely studied as an idealized model of the processes in the surf zone. Figure 2(a) delineates the model. The bore is initially a sharp front of water on the beach of slope angle $\theta$ with the horizontal. The velocity $u_{o}$ and depth $h_{o}$ of the bore are initially constant behind the front. The collapse of the bore causes the water in the bore to run up the slope. Subsequently, the water down washes the slope upon reaching the maximum runup height $R_{\max }$. The very tip of the water on the slope is the shoreline. The advancing and receding shoreline on the slope is one of the most challenging numerical problems when the classical finite-volume methods are employed to solve it. The water depth vanishes to zero at the shoreline. Spurious numerical oscillations can lead to negative water depth and subsequent breakdown of the numerical simulation. However, these classical numerical oscillation problems are completely eliminated when the LBH method are employed for the runup and overtopping simulations.
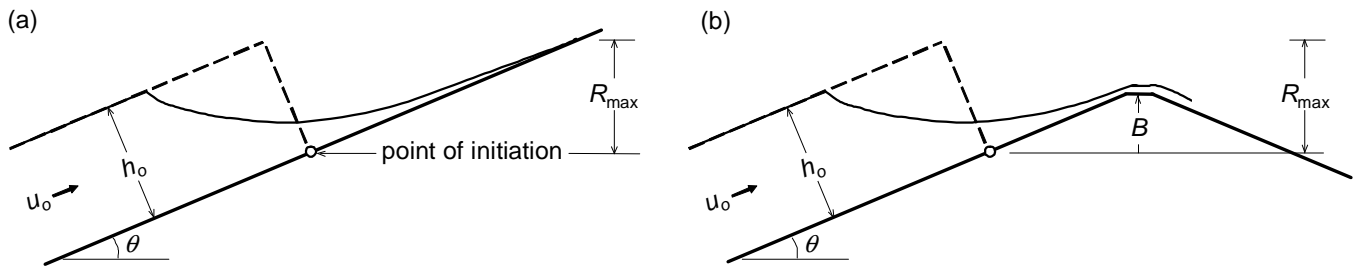

Figure 2. (a) Collapsing bore of Shen \& Meyer (1963) with initial velocity $u_{o}$ and initial depth $h_{o}$ on a slope of angle $\theta$, (b) collapsing bore overtopping a levee of berm height $B$ above its point of initiation.

Three collapsing bores with the same initial water depth $h_{o}=0.6 \mathrm{~m}$ but different initial velocity $u_{o}$ and beach slope $S_{o}$ are computed using the LBH method. The comparison of the computation results obtained using $\Delta x=0.001 \mathrm{~m}$ with the exact solutions is shown in Figs. 3 and 4 . Table 1 summarizes the initial conditions and the simulation results that are obtained by extrapolation to zero block size.

\begin{tabular}{|c|c|c|c|}
\hline Slope $S_{o}$ & $\begin{array}{c}\text { Initial velocity } \\
u_{t=0}\end{array}$ & $\begin{array}{l}\text { Maximum runup height } \\
\left(R_{\max }\right)_{\Delta x \rightarrow 0}(\mathrm{~m})\end{array}$ & $\begin{array}{l}\text { Maximum Overtopping } \\
\text { volume }\left(V_{\text {OTmax }}^{*}\right)_{\Delta x \rightarrow 0}\end{array}$ \\
\hline $1 \mathrm{v}: 1 \mathrm{~h}$ & 0 & 0.880 & 0.151 \\
\hline $1 \mathrm{v}: 2 \mathrm{~h}$ & 0 & 0.985 & 0.169 \\
\hline $1 \mathrm{v}: 1 \mathrm{~h}$ & $\left(g h_{0}\right)^{1 / 2}$ & 2.07 & 0.165 \\
\hline
\end{tabular}

The exact solutions for the depth and velocity of the collapsing bore as given by Shen \& Meyer (1963) and Peregrine \& Williams (2001) are:

$$
\begin{gathered}
h^{*}=\frac{1}{9 t^{* 2}}\left(x_{s}^{*}-x^{*}\right)^{2} \\
u^{*}+t^{*}=\frac{2}{3}\left(\frac{x^{*}-x_{s}^{*}}{t^{*}}\right)
\end{gathered}
$$


The dimensionless variables in these exact solutions are $h^{*}=2 h \cos \theta / R_{\max }, x^{*}=2 x \sin \theta / R_{\max }, x_{s}^{*}=2 t^{*}-$ $t^{* 2} / 2, t^{*}=t \sin \theta\left(2 g / R_{\max }\right)^{1 / 2}$ and $u^{*}=u \sin \theta\left(2 / g R_{\max }\right)^{1 / 2}$, which are based on the normalization by the maximum runup height $R_{\max }$. The dimensionless position of the shoreline is $x_{s}{ }^{*}$.

The position of the shoreline is a parabola according to the exact solution given by Eqs. 3 and 4 . The water rises to the top of the parabola at the maximum height $R_{\max }$ and then falls back symmetrically. At the maximum height, $x^{*}=2 x \sin \theta / R_{\max }=2$. The LBH simulation data of the three collapsing bores denoted by the circle, triangular and cross symbols all follow very closely the exact solution of the parabola as shown in Fig. 3. The depth and velocity of the collapsing bore profiles, if normalized by the initial depth $h_{o}$ and initial velocity $u_{o}$, would be time dependent as shown in Fig. 4(a,b). The different profiles at different times collapse onto one depth and one velocity profiles as shown in Fig. 4(c,d) when the results are presented in terms of the swash coordinates, namely (i) when the length scale of the normalization is the maximum runup height $R_{\max }$ and (ii) when the coordinates are measured relative to the position of the shoreline $x_{s}{ }^{*}$.

The LBH simulation results in Fig. 3 and Fig. 4(c,d) are obtained using the small block size of $\Delta x=$ $0.001 \mathrm{~m}$. Improvement of the results are obtained by the refinement of the block size and then by the extrapolation of the results as block size $\Delta x$ approaches zero. Figure 5 shows the convergence towards the solution $\left(R_{\max }\right)_{\Delta x \rightarrow 0}$ as the block size $\Delta x \rightarrow 0$. The convergence toward the exact solution is slow in this case when the bed friction is ignored in the simulation. The frictionless shoreline of the collapsing bore is a rather difficult numerical problem because the depth of the front vanishes to zero following the quadratic relation Eq. 3. However, as it will be demonstrated later, much faster rate of convergence can be obtained in other runup problems when the bed friction is included in the simulation of the shoreline.

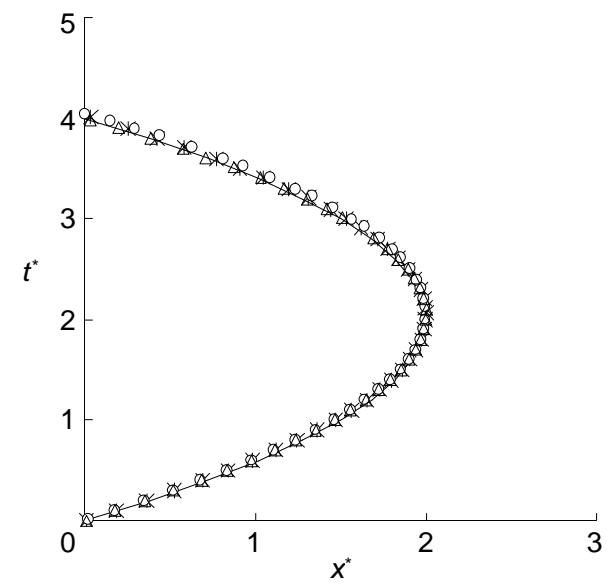

Figure 3. Shoreline trajectory for three collapsing bores: $u_{o}=0, S_{o}=1 \mathrm{v}: 1 \mathrm{~h}$ (circle), $u_{o}=0, S_{o}=1 \mathrm{v}: 2 \mathrm{~h}$ (triangle), and $u_{o}=\left(g h_{o}\right)^{1 / 2}, S_{o}=1 \mathrm{v}: 1 \mathrm{~h}$ (cross). The exact solution of Shen \& Meyer (1963) is the solid line. Initial bore height is $h_{0}=0.6 \mathrm{~m}$ and mesh size is $\Delta x=0.001 \mathrm{~m}$.

Table 1 summarizes the extrapolations result from the grid refinement. The maximum runup height is $\left(R_{\max }\right)_{\Delta x \rightarrow 0}=0.880 \mathrm{~m}$ and $0.985 \mathrm{~m}$ for the cases of zero initial velocity $u_{o}=0$ and beach slope $S_{o}=$ $1 \mathrm{v}: 1 \mathrm{~h}$ and $1 \mathrm{v}: 2 \mathrm{~h}$, respectively, and is as high as $\left(R_{\max }\right)_{\Delta x \rightarrow 0}=2.07 \mathrm{~m}$ when the bore is projected upward with a non-zero initial velocity $u_{o}=\left(g h_{o}\right)^{1 / 2}$. The simulation results are independent of the initial conditions $u_{o}$ and $h_{o}$ only when the results are expressed in terms of the swash coordinates. It should be noted that Eqs. 3 and 4 is a special solution of the problem that does not depend on the conditions at the seaward side of the waves. In particular, it does not provide any information regarding the maximum runup height $R_{\max }$. 

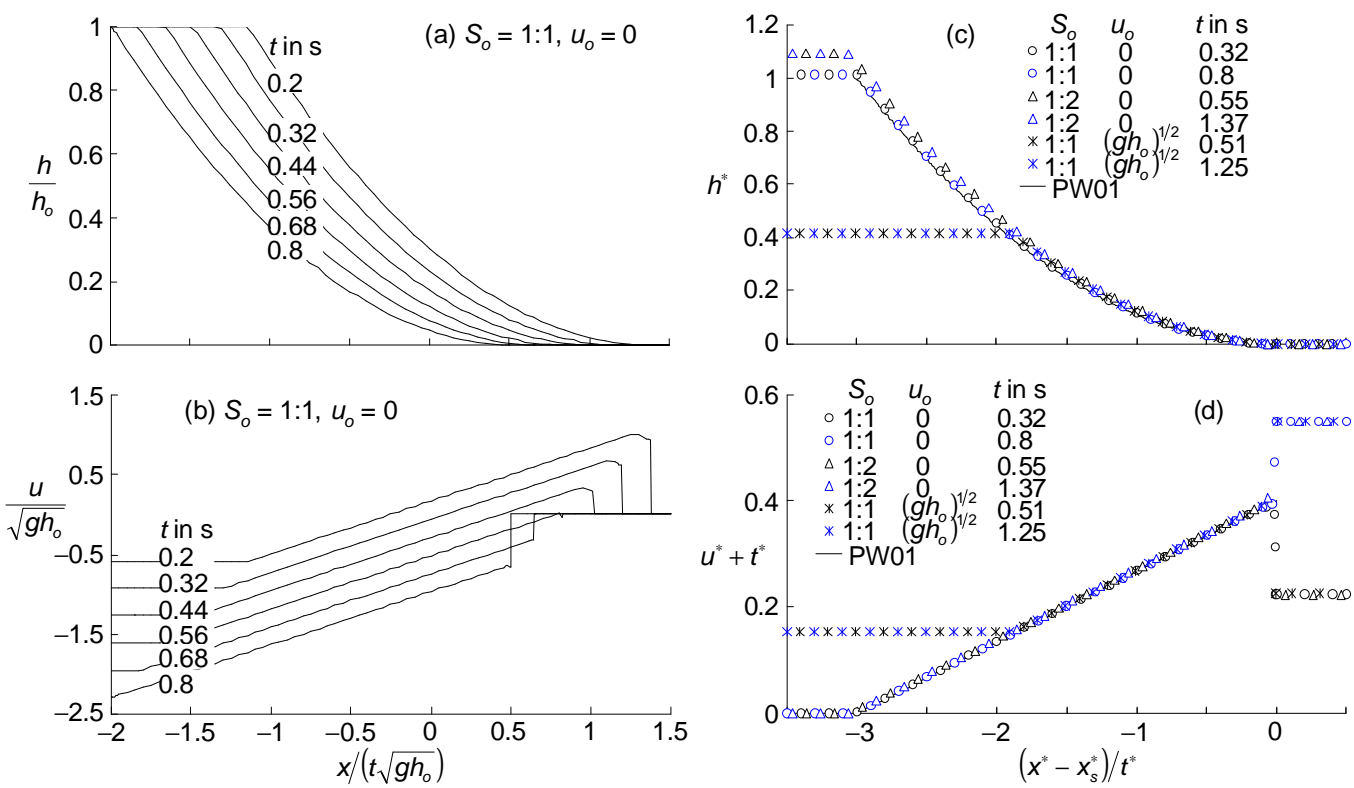

Figure 4. (a,b) Profiles of a collapsing bore on a $1 \mathrm{v}: 1 \mathrm{~h}$ slope over a period of time from $t=0.2 \mathrm{~s}$ to $0.8 \mathrm{~s}$. Depth and velocity profiles normalized using the initial water depth $h_{o}$ as the length scale, (c,d) depth and velocity profiles normalized by the maximum runup height $\boldsymbol{R}_{\max }$.

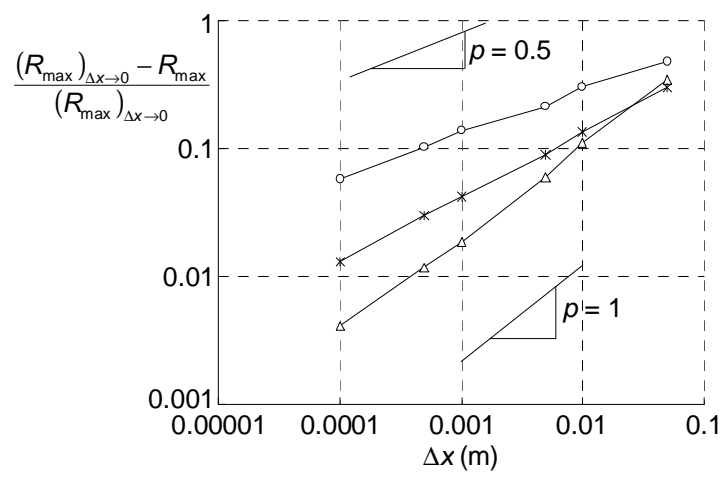

Figure 5. Error reduction with block size that shows the convergence of the maximum runup height toward the true solution $\left(R_{\max }\right)_{\Delta x \rightarrow 0}$.

\section{COLLAPSING BORE - OVERTOPPING}

Peregrine \& Williams (2001) have utilized a truncated solution of Eqs. 3 and 4 to find the following analytical solution for the volume of water overtopping the levee when the berm height of the levee $B$ is lower than the maximum runup height $R_{\max }$ as shown in Fig. 2b:

$$
V_{\mathrm{OT}}^{*}=\frac{1}{27}\left(4-12 B^{*}+8 B^{*} \sqrt{2 B^{*}}-3 B^{* 3}\right)
$$

where $V_{\text {OT }}^{*}=2 V_{\text {OT }} \sin 2 \theta / R_{\text {max }}^{2}$ and $B^{*}=2 B / R_{\max }$. According to this truncated solution, the maximum overtopping volume $V_{\text {OTmax }}^{*}=0.15$ occurs when the berm height $B^{*}$ is zero, that is when the crest of the levee is at the same height as the point of initiation of the collapsing bore. 
Figure 6 compares the truncated solution Eq. 5 with the LBH computation results. Table 1 summarizes the maximum overtopping volume which are $\left(V_{\text {OTmax }}^{*}\right)_{\Delta x \rightarrow 0}=0.151,0.169$ and 0.165 obtained for the three collapsing bores. These results as shown in the figure and summarized in the table are extrapolation for $\Delta x \rightarrow 0$ from the grid refinement data. The agreement of the LBH computations with Eq. 5 is good but not perfect. The computation for the overtopping volume should be to some extent dependent on the boundary condition at the truncated end of the beach. In the present computation, the elevation of the water surface beyond the truncated beach is assumed to be one $h_{o}$ below the point of initiation point (see Fig. 1). The consequence of this assumption is that a huge unrealistic pressure gradient being artificially imposed at the line of truncation. Despite of this unrealistic condition, the overtopping volume is realistically determined in the sense that the simulated results of $\left(V_{\text {OTmax }}^{*}\right)_{\Delta x \rightarrow 0}=0.151,0.169$ and 0.165 are very close to the theoretical value of $V_{\text {OTmax }}^{*}=$ 0.15 obtained by Peregrine \& Williams (2001).

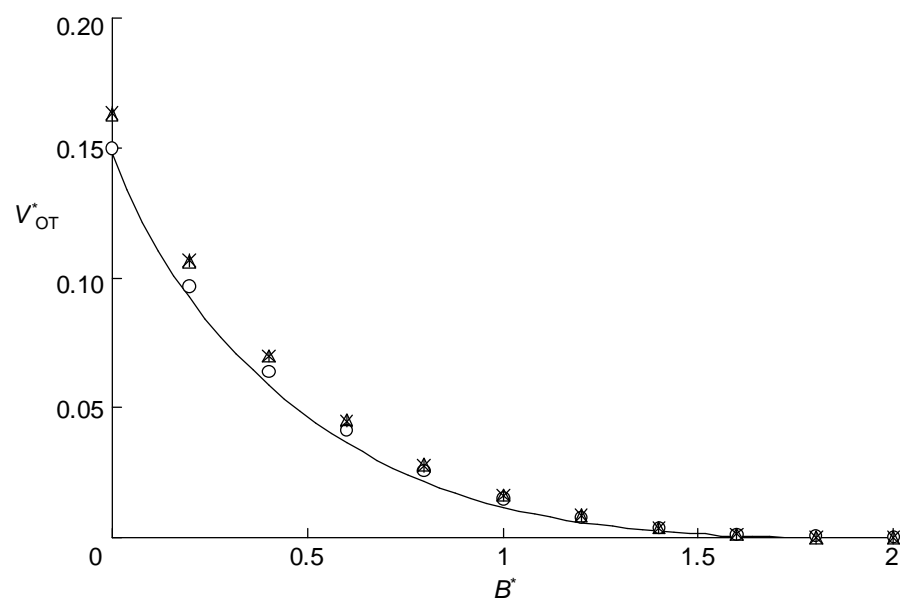

Figure 6. Overtopping volume $V^{\star}$ от versus berm height $B^{\star}$. The line is the analytical solution of Peregrine \& Williams (2001). Initial bore height is $h_{o}=0.6 \mathrm{~m}$.

\section{SOLITARY-WAVE RUNUP}

The second series of runup and overtopping simulations is conducted for the solitary waves on plane beach with bed-friction. Many experiments for the runup of the solitary waves on smooth plane beach have been conducted in the laboratory. The vast amount of laboratory data available is used to validate the runup simulations by the LBH method. In the present simulation of the solitary waves, the friction coefficient of the hydrodynamically smooth surface is calculated using a formula given in a previous paper by Tan \& Chu (2009a). The initial location of the solitary waves is located in a position as described in Synolakis (1986) and in Tan \& Chu (2010a). Typical simulated runup depth and velocity profiles were presented in the previous paper. However, a much more comprehensive series of LBH simulations of the solitary waves has been completed recently. Only the results obtained for the maximum runup height $R_{\max }$ are presented in this paper.

Figure 7 compared the simulated maximum runup height with six series of laboratory data. The beach slopes $S_{o}$ for the six laboratory experiments are (a) $S_{o}=1 \mathrm{v}: 5.375 \mathrm{~h}$ (Jensen et al. 2003), (b) $S_{o}=$ 1v:5.67h (Hall \& Watts 1953), (c) $S_{o}=1 \mathrm{v}: 15 \mathrm{~h}$ (Li \& Raichlen 2002), (d) $S_{o}=1 \mathrm{v}: 19.85 \mathrm{~h}$ (Synolakis 1986), (e) $S_{o}=1 \mathrm{v}: 30 \mathrm{~h}$ (Briggs et al. 1995) and (f) $S_{o}=1 \mathrm{v}: 60 \mathrm{~h}$ (Hsiao et al. 2008). The LBH simulation data in the figure are calculated based on the extrapolation of the results obtained from the block refinement study. When friction is included in the simulation, the convergence of results to the true solution $\Delta x=0$ is very fast (see Tan \& Chu 2010b). Therefore, the extrapolation results for zero block size $\Delta x=0$ as presented in Fig. 7 are highly reliable. In the figure, the maximum runup height is normalized by the undisturbed depth of water $d$, as most of the laboratory data were presented in this manner. The initial amplitude of the solitary waves $a$ are selected in the simulation to be the same as the laboratory experiments. The LBH simulations for the maximum runup height $R_{\max }$ have been conducted 
with and without bed-friction. The results in the figure clearly show the effect of the friction on the runup height. The effect is most significant for waves of large wave steepness $a / d$ on a milder slope. The example is the series of experiments by Hsiao et al. (2008), which was conducted on a 1v:60h slope in a very large 300-m long wave flume. The runup height is reduced by as much as a factor of 2 when the bed friction is included in the simulation of Hsiao et al's laboratory experiments.

The validation of the simulation results using (i) the exact solutions of the collapsing bore and (ii) the laboratory data of the solitary waves as reported in the previous sections has given confidence to the LBH method. The computational stability clearly is an advantage of the LBH method over other numerical computation methods. Structural porosity, roughness, slope and other topographical variations can be readily included in the LBH numerical simulations to find the optimal design of the structures.
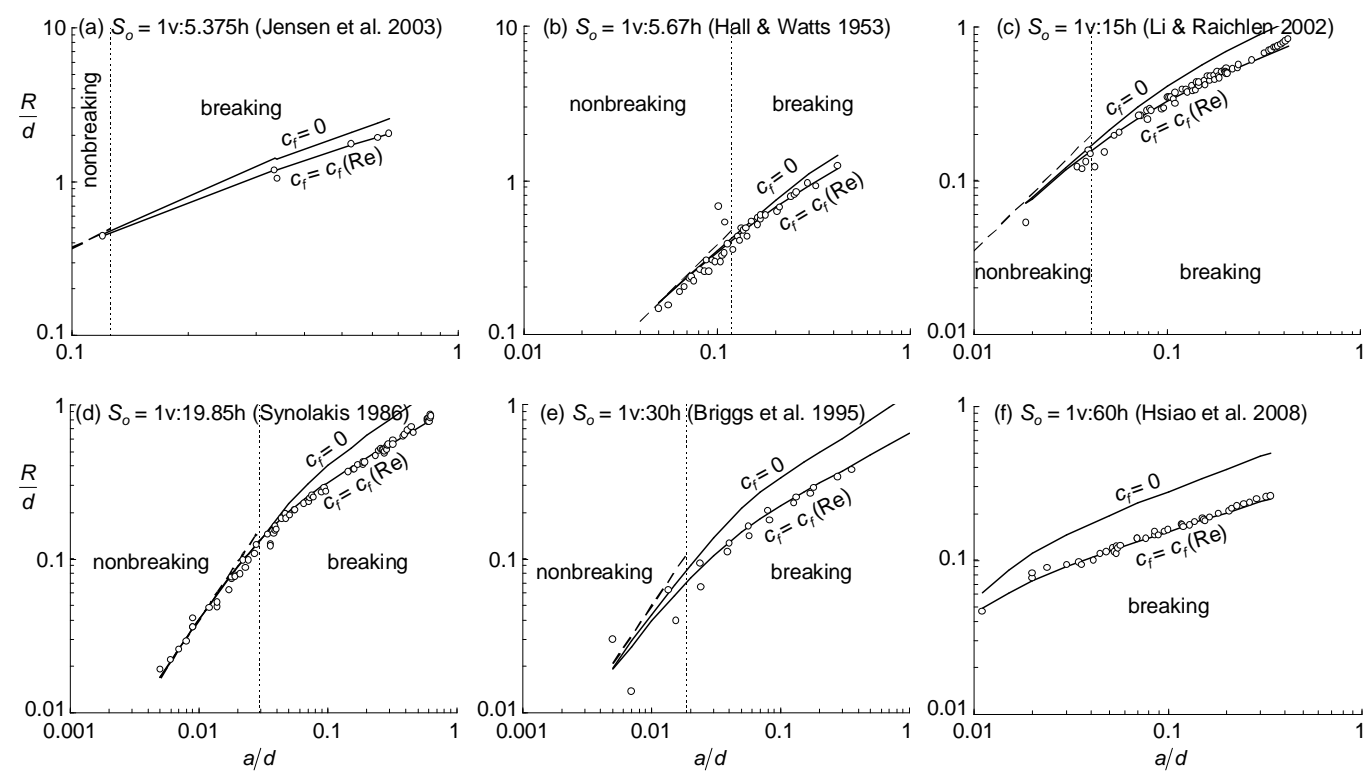

Figure 7. The maximum runup height $\boldsymbol{R}_{\max }$ for solitary waves on six different slopes $S_{o}=1 \mathrm{v}: 5.375 \mathrm{~h}, 1 \mathrm{v}: 5.67 \mathrm{~h}$, $1 \mathrm{v}: 15 \mathrm{~h}, 1 \mathrm{v}: 19.85 \mathrm{~h}, 1 \mathrm{v}: 30 \mathrm{~h}$ and $1 \mathrm{v}: 60 \mathrm{~h}$.

\section{PERIODIC-WAVE RUNUP AND OVERTOPPING}

The shoaling of the periodic-wave is by far the most difficult numerical problem. The overtopping of levee by the periodic waves has not been attempted in any previous numerical simulation. Therefore, the LBH simulations of the periodic waves are carried out here as a numerical challenge to demonstrate further application of the LBH method. In the simulation of the periodic waves, a wave maker is the periodic supply and removal of water from an array of cells at the seaward side of the computation domain. The LBH simulations are carried out for two wave heights $H_{o}=0.332 \mathrm{~m}$ and $H_{o}=0.064 \mathrm{~m}$, shoaling on three different beach slopes $S_{o}=1 \mathrm{v}: 1 \mathrm{~h}, 1 \mathrm{v}: 2 \mathrm{~h}$, and $1 \mathrm{v}: 4 \mathrm{~h}$. The conditions of the simulations are summarized in Table 2.

\begin{tabular}{|c|c|c|c|c|}
\hline \multirow[t]{2}{*}{ Slope $S_{o}$} & \multicolumn{2}{|c|}{$H_{0}=0.332 \mathrm{~m}$} & \multicolumn{2}{|c|}{$H_{0}=0.064 \mathrm{~m}$} \\
\hline & $\left(R_{\max }\right)_{\Delta x \rightarrow 0}(\mathrm{~m})$ & $\left(V_{\mathrm{OT}}^{*}\right)_{\Delta x \rightarrow 0}$ & $\left(R_{\max }\right)_{\Delta x \rightarrow 0}(\mathrm{~m})$ & $\left(V_{\mathrm{OT}}^{*}\right)_{\Delta x \rightarrow 0}$ \\
\hline $1 \mathrm{v}: 1 \mathrm{~h}$ & 0.755 & 0.149 & 0.288 & 0.174 \\
\hline $1 \mathrm{v}: 2 \mathrm{~h}$ & 0.386 & 0.155 & 0.270 & 0.162 \\
\hline $1 \mathrm{v}: 4 \mathrm{~h}$ & 0.150 & 0.162 & 0.137 & 0.159 \\
\hline
\end{tabular}



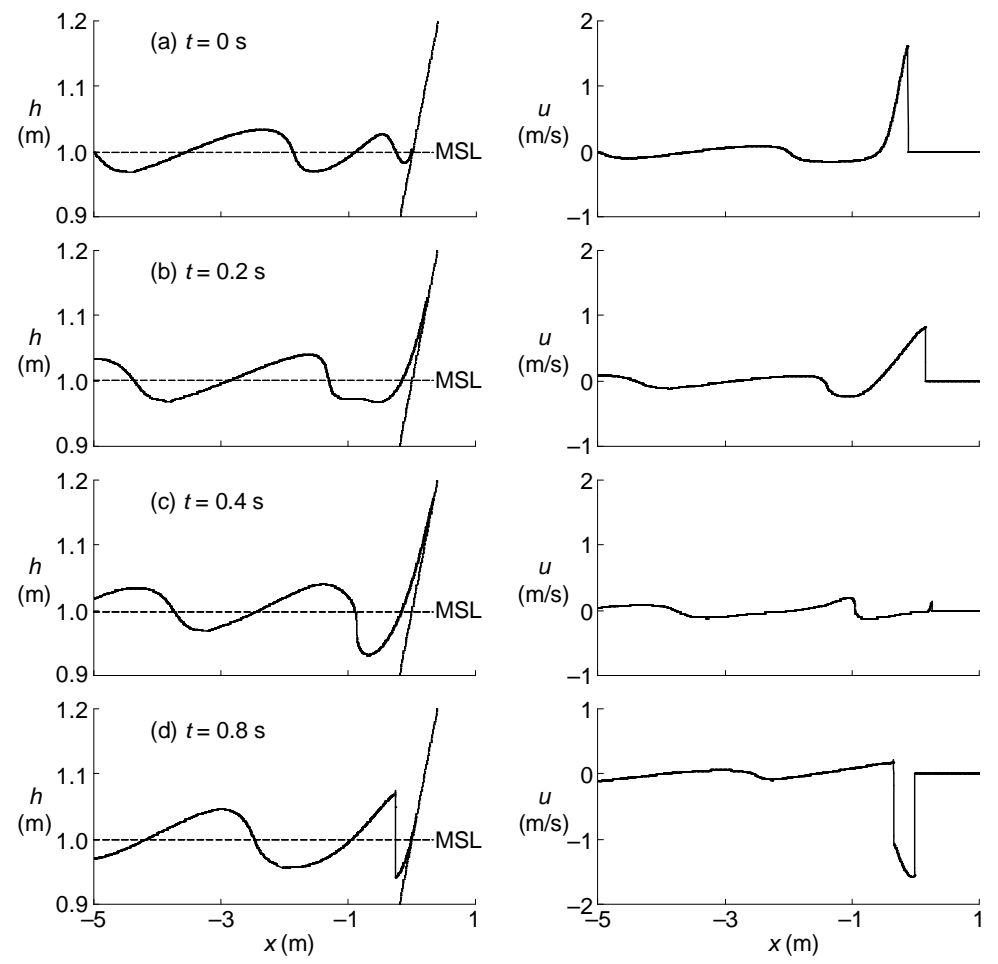

Figure 8. Surface elevation (left) and the corresponding velocity (right) profiles of a periodic wave $\boldsymbol{H}_{0}=\mathbf{0 . 0 6 4}$ $m$ runs up and downwashes on a beach of slope $S_{o}=1 \mathrm{v}: 2 \mathrm{~h}$.
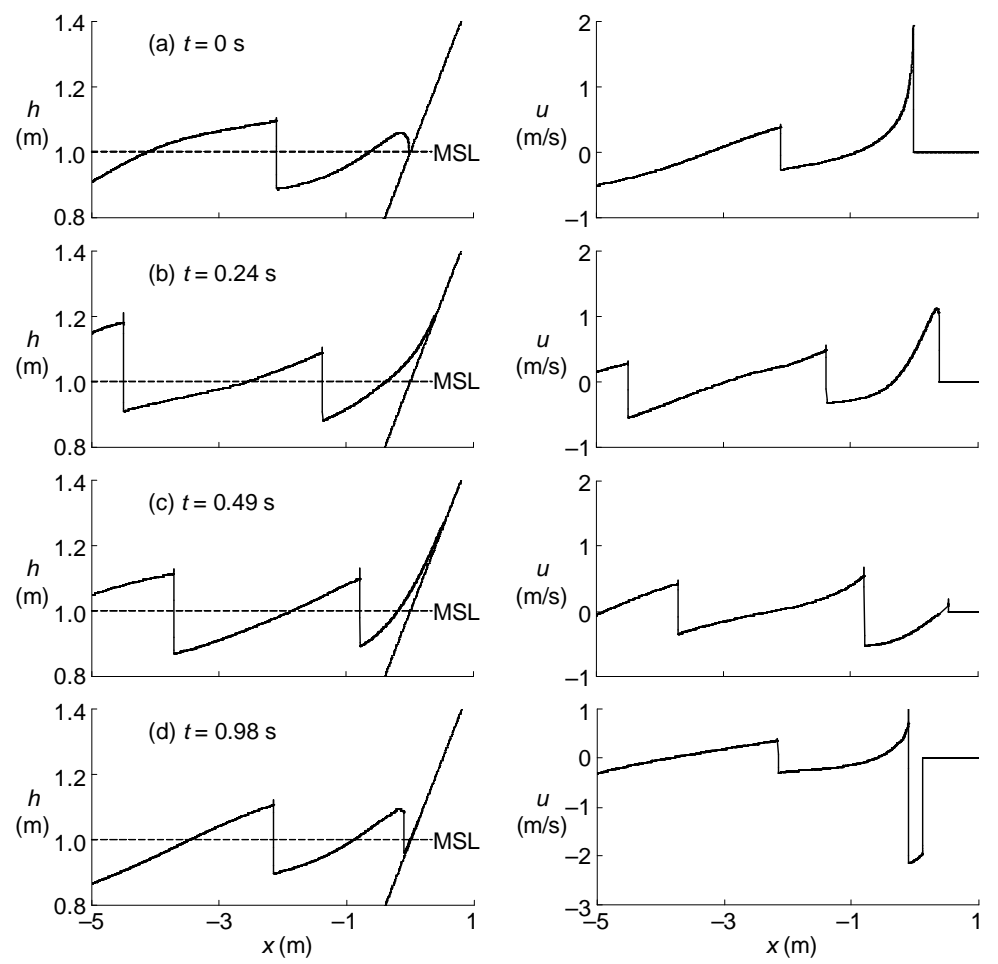

Figure 9. Surface elevation (left) and the corresponding velocity (right) profiles of a periodic wave $\boldsymbol{H}_{0}=\mathbf{0 . 3 3 2}$ $m$ runs up and downwashes on a beach of slope $S_{o}=1 \mathrm{v}: 2 \mathrm{~h}$. 
Two typical depth and velocity profiles on a $1 \mathrm{v}: 2 \mathrm{~h}$ beach slope obtained from the LBH simulations over a time period of one wave cycle are given in Figs. 8 and 9. Figure 8 shows the profiles of a relatively small amplitude wave of $H_{o}=0.064 \mathrm{~m}$, and Figure 9, the profiles of a larger amplitude wave of $H_{o}=$ $0.332 \mathrm{~m}$. The simulation of the periodic runup is a challenging numerical problem. Besides tracking the movement of water runup and downwash the beach slope, the computation scheme must be able to capture the wave breaking as the water on the slope downwash and collide with the incoming waves. The waves of the smaller amplitude on a steep slope do not break. On the other hand, breaking is a certainty in the waves of large amplitude on a mild slope. The swash event starts with a high velocity at the shoreline. This is followed by the runup of water on the slope which eventually reaches the maximum height $R_{\max }$. The velocity at the shoreline is zero when the runup of wave reaches the maximum. The downwash of water follows the maximum runup. The end of the cycle is the formation of a surge as the shoreward incoming wave meets the downward swash along the slope. As shoreline moves up and down along the beach, the LBH simulations of the waves are not interrupted by any computational instability. Taking advantage of the computational stability of the method, the computations are carried out to determine (i) the maximum runup height $R_{\max }$ as shown in Fig. 10(a) and (ii) the overtopping volume when the berm height $B$ is below the maximum runup height as shown in Fig. 10(b). Six simulations of the periodic waves are conducted for two wave heights $H_{o}=0.332 \mathrm{~m}$ and $H_{o}=0.064 \mathrm{~m}$ and three beach slopes $S_{o}=1 \mathrm{v}: 1 \mathrm{~h}, S_{o}=1 \mathrm{v}: 2 \mathrm{~h}$ and $S_{o}=1 \mathrm{v}: 4 \mathrm{~h}$. All waves has a wave period of $T_{o}=1 \mathrm{~s}$ and an undisturbed water depth at the toe of the beach $d=1 \mathrm{~m}$. The wave length for all waves is $L_{\mathrm{o}}=(g d)^{1 / 2} T_{o}=3.13 \mathrm{~m}$.
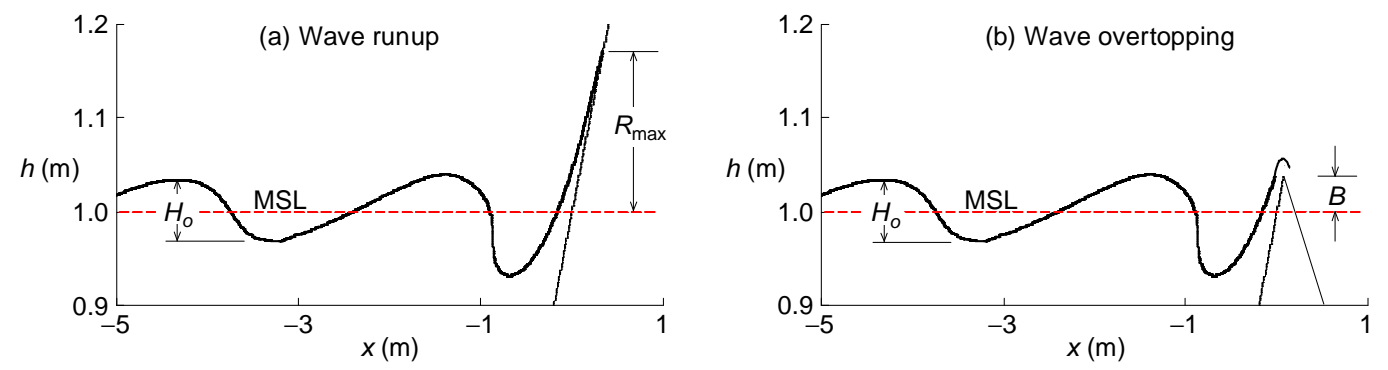

Figure 10. (a) Runup of periodic waves to a maximum height of $\boldsymbol{R}_{\max }$, (b) Periodic-wave overtopping a levee of berm height $B$.

\section{Shoreline Trajectory and Maximum Runup Height}

Figure 11 shows the shoreline trajectory for the series of six simulations of the periodic waves. The shoreline height $R(t)$ moves up and down on the slope during the shoaling of the periodic waves into the shallower water. The rise and fall of the shoreline near the maximum runup follow closely to a parabolic trajectory. The downwash of the waves on the slope however is dependent on the wave height and the slope of the beach. In some cases, the shoreline may fall below the mean sea level (MSL) when the beach slope is sufficiently large. The maximum runup height $R_{\max }$ for each simulation is determined from the shoreline trajectories shown in Fig. 11. The dimensionless shoreline height $R /\left(H_{o} \xi_{o}\right)$ is defined in term of the surf similarity parameter. Introduced by Battjes (1974), the surf similarity parameter is related to the slope angle $\theta$, the wave height $H_{o}$ and the initial wave length $L_{o}$ as follows:

$$
\xi_{o}=\tan \theta\left(\frac{H_{o}}{L_{o}}\right)^{-\frac{1}{2}}
$$

The period of the swash event in periodic waves is remarkably close to the one obtained for the collapsing bore. Therefore, the same dimensionless time $t^{*}=t \sin \theta\left(2 g / R_{\max }\right)^{1 / 2}$ are used to present the simulation results in Fig. 11. The Coastal Engineering Manual (Walton et al. 1989) has recommended two formulae for the maximum runup height. One of the formulae due to Hunt (1959) is: 


$$
\frac{R_{\max }}{H_{o}}=\xi_{o} \text { for } 0.1<\xi_{\mathrm{o}}<2.3
$$

The simulated maximum runup heights of the periodic waves are all below the value recommended by the Hunt's formula. It should be pointed out that the Hunt's formula is for regular waves. The regular waves are random in phase and amplitude. The collision of events in the regular waves of same significant wave height and amplitude should produce greater runup than the periodic waves.
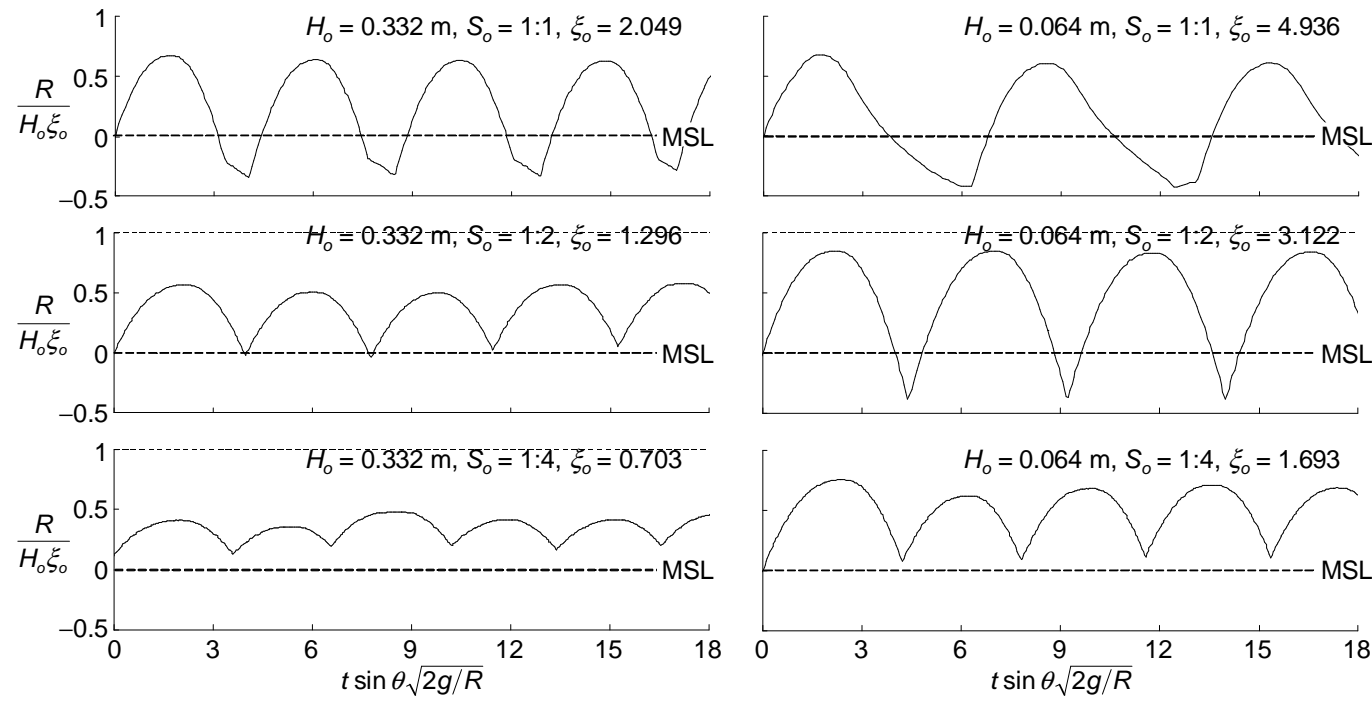

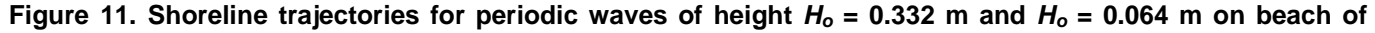
slopes $S_{o}=1 \mathrm{v}: 1 \mathrm{~h}, 1 \mathrm{v}: 2 \mathrm{~h}$, and $1 \mathrm{v}: 4 \mathrm{~h}$ using $\Delta x=0.001 \mathrm{~m}$.

\section{Periodic Waves and the Collapsing Bore}

The collapsing bore, and particularly the swash solution of Peregrine \& Williams (2001), has been considered as a model of the processes in the surf zone. It is therefore interesting to see whether the periodic-wave simulation results may be related to the collapsing bore. Figure 12 shows the shoreline trajectory of the periodic waves normalized by the swash variables of the collapsing bore. If the time origin is defined by the intersection of the shoreline with MSL, the normalized shoreline trajectory would match closely the collapsing bore's parabolic profile defined by Eqs. 3 and 4. The initiation of the collapsing bore starts at time $t^{*}=0$. Therefore, the corresponding initiation time for the periodic waves is defined at a time when the shoreline meets the MSL. The time $t^{*}=t_{1}, t_{2}$ and $t_{3}$ are quarter, half and three quarter of one runup and downwash cycle. The parabolic shoreline trajectory fits well the data over the period close to the maximum runup. It does not always fit the data in other period of time particularly for waves of small amplitude. In the cases with steep slopes, the downwash is relatively strong and shoreline dives below the MSL some of the time as shown in Fig. 12. The time for the water on the beach to rise from MSL to the maximum runup height $R_{\max }$ and back to the MSL is $t_{0 \rightarrow 4}^{*}=t_{0 \rightarrow 4}$ $\sin \theta\left(2 g / R_{\max }\right)^{1 / 2} \approx 4$, which is approximately the same as the collapsing bore.

Figure 13 compared the depth and velocity profiles of the periodic waves with the swash solution of the collapsing bore. The data are plotted using the swash variables of Peregrine \& Williams (2001). The line identified as PW01 is the swash solution of Eqs. 3 and 4. The depth and velocity profiles data for time $t=t_{1}, t_{2}$ and $t_{3}$ are all greater than the swash solution PW01. The periodic waves have produced a much stronger swash event that is entirely different from the swash event of the collapsing bore. It is clear from Fig. 13 that the profiles of the periodic waves are different. The incoming waves interact continuously with the downwash of water. The interaction causes the waves to break. The breaking wave is a prominent feature of the shoaling periodic waves. It is however a phenomena completely missing in the solution for the collapsing bore. 

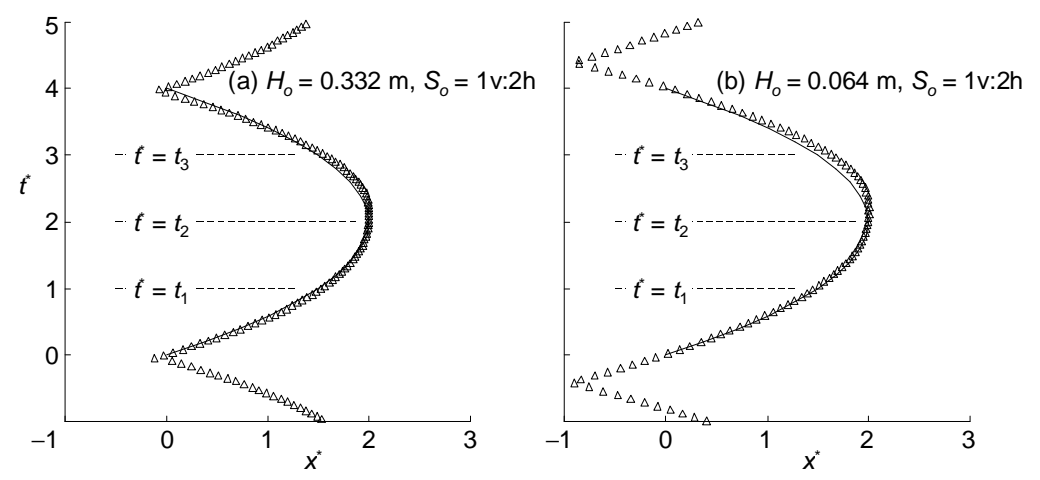

Figure 12. Shoreline trajectory for one wave period of the periodic wave plotted using the swash variables. The triangle symbol denotes the simulated shoreline trajectory of the periodic wave and the solid line is Eqs. 3 and 4 for the collapsing bore.
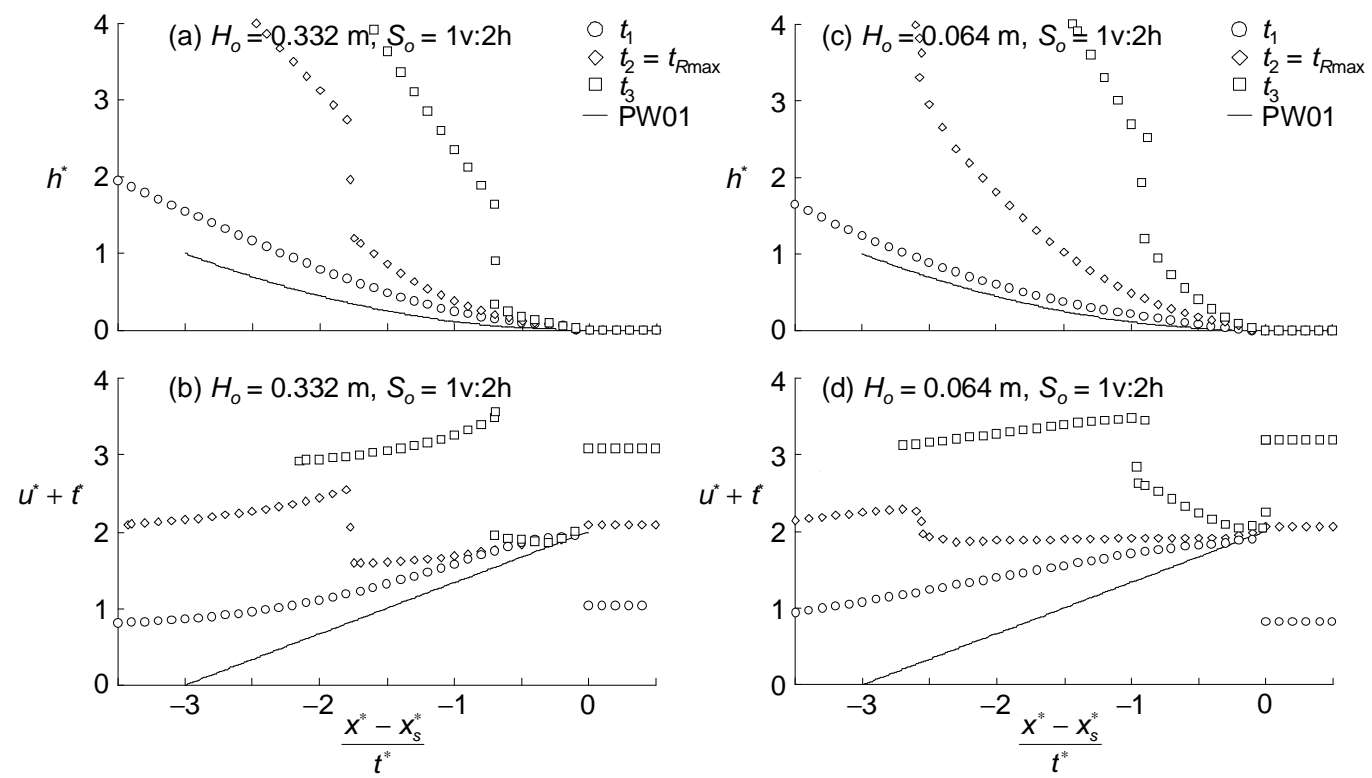

Figure 13. Depth and velocity profiles of two periodic waves expressed in terms of the swash variables; (a-b) $H_{o}=0.332 \mathrm{~m}$, and (c-d) $H_{o}=0.064 \mathrm{~m}$ in the surf zone at time $t=t_{1}$ (circle), $t_{2}$ (diamond) and $t_{3}$ (rectangle). The collapsing-bore solution of Peregrine \& Williams (2001) is identified as PW01.

\section{Grid Refinement and Extrapolation for the Maximum Runup Height}

Accurate determination of the maximum runup height $R_{\max }$ of the periodic waves is obtained from a series of block-refinement simulations. Figure 14 shows the convergence of the maximum runup height towards the value corresponding to zero block size $\left(R_{\max }\right)_{\Delta x \rightarrow 0}$. The rate of convergence is rapid in these simulations of the shoreline. Table 3 summarizes the extrapolation values $\left(R_{\max }\right)_{\Delta \mathrm{x} \rightarrow 0}$ for the periodic waves and the comparisons with the two formulae recommended by the Coastal Engineering Manual (Walton et al. 1989). Figure 15 correlates the dimensionless runup height $\left(R_{\max }\right)_{\Delta x \rightarrow 0} / H_{o}$ with the surf similarity parameter $S_{o}\left(H_{o} / L_{o}\right)^{-1 / 2}$. The formulae of van der Meer (2002) for regular waves are included in the figure for comparison. The Hunt's (1959) formula is recommended when $S_{o}\left(H_{o} / L_{o}\right)^{-1 / 2}<2$. The LBH simulation follows the trend of the van der Meer's formula. However, the maximum runup height of the periodic waves is expected to be below the regular (random) waves of the same significant wave height and wave period. The collision of the random events of the regular waves can briefly lead to much greater wave height than the significant wave height. 

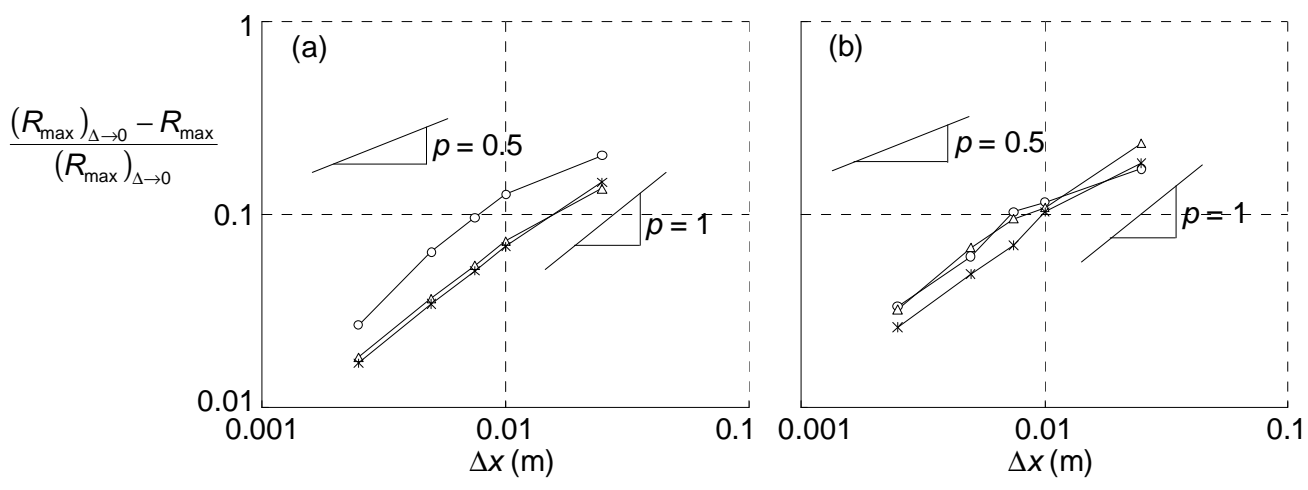

Figure 14. Convergence of the maximum runup height of periodic waves toward $\left(R_{\max }\right)_{\Delta x \rightarrow 0}$ for (a) $H_{o}=0.332$ $\mathrm{m}$, and (b) $H_{o}=0.064 \mathrm{~m}$ on slopes of $S_{o}=1 \mathrm{v}: 1 \mathrm{~h}$ (circle), $1 \mathrm{v}: 2 \mathrm{~h}$ (triangle), and 1v:4h (cross).

\begin{tabular}{|c|c|c|c|c|c|}
\hline \multirow{2}{*}{ Ho } & \multirow{2}{*}{ So } & \multirow{2}{*}{$\left(R_{\max }\right)_{\Delta x \rightarrow 0}(\mathrm{~m})$} & \multicolumn{3}{|c|}{$\frac{\left(R_{\max }\right)_{\Delta x \rightarrow 0}}{H_{0}}$} \\
\hline & & & LBH & Hunt (1959) & $\begin{array}{c}\text { Miche }(1951) \& \\
\text { Keller }(1961)\end{array}$ \\
\hline 0.332 & $1 \mathrm{v}: 1 \mathrm{~h}$ & 0.755 & 1.416 & 3.071 & 2.806 \\
\hline 0.332 & $1 \mathrm{v}: 2 \mathrm{~h}$ & 0.386 & 0.828 & 1.536 & 3.337 \\
\hline 0.332 & $1 \mathrm{v}: 4 \mathrm{~h}$ & 0.150 & 0.331 & 0.768 & 3.969 \\
\hline 0.064 & $1 \mathrm{v}: 1 \mathrm{~h}$ & 0.288 & 2.828 & 6.976 & 2.806 \\
\hline 0.064 & $1 v: 2 h$ & 0.270 & 2.804 & 3.488 & 3.337 \\
\hline 0.064 & $1 v: 4 h$ & 0.137 & 1.438 & 1.744 & 3.969 \\
\hline
\end{tabular}

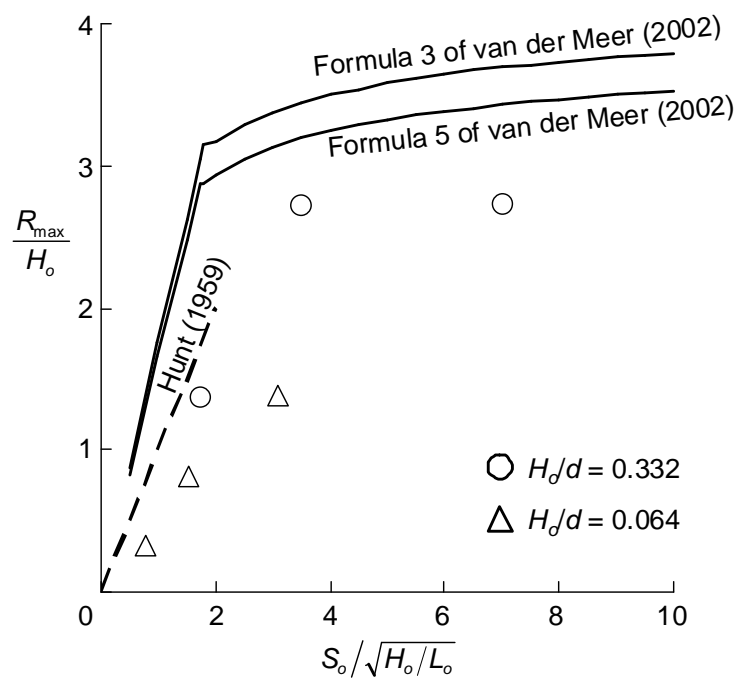

Figure 15. Correlation of the maximum periodic-wave runup $\left(R_{\max }\right)_{\Delta x \rightarrow 0}$ and comparison with the van der Meer (2002) and Hunt (1959) formulae.

\section{Periodic Wave Overtopping over Truncated Beach}

Water would intermittently flow over the levee if the berm height of the levee $B$ is lower than the maximum runup height $R_{\max }$. The shoaling of the periodic waves causes the water to run up the slope on the front face of the levee, flow overtop the levee and then retreats below the berm. Figure 16 shows the 
intermittent flow over the levee for the two waves (a) $H_{o}=0.332 \mathrm{~m}$ and (b) $H_{o}=0.064 \mathrm{~m}$ on the slope $S_{o}=1 \mathrm{v}: 2 \mathrm{~h}$. The dimensionless flow rate over the levee $q^{*}=q \cos \theta /\left[g\left(R_{\max } / 2\right)^{3}\right]^{1 / 2}$ depends on the berm height $B$ above the mean sea level. The overflow is zero in the limit when the dimensionless berm height $B^{*}=2 B / R_{\max }=2$. The volume of the overtopped water per wave $V_{\mathrm{O}}$ is determined by time integration of the flow rate over the period of one wave. The dimensionless overtopping volume per wave for the periodic waves $V_{\text {OT }}^{*}=2 V_{\text {OT }} \sin 2 \theta / R_{\text {max }}^{2}$ is compared with the collapsing-bore solution Eq. 5 of Peregrine \& Williams (2001) and experiment data of Baldock et al. (2005) in Fig. 17. The LBH simulation results give much larger overtopping volume then the swash solution of the collapsing bore. They are however consistent in trend and in the same range as the laboratory data of Baldock et al. (2005). Figure 18 is the correlation of the overtopping volume of the periodic waves with the wave height $H_{o}$ and wave length $L_{o}$. The maximum runup height is not required to find the overtopping volume from this direct correlation shown in Fig. 18.
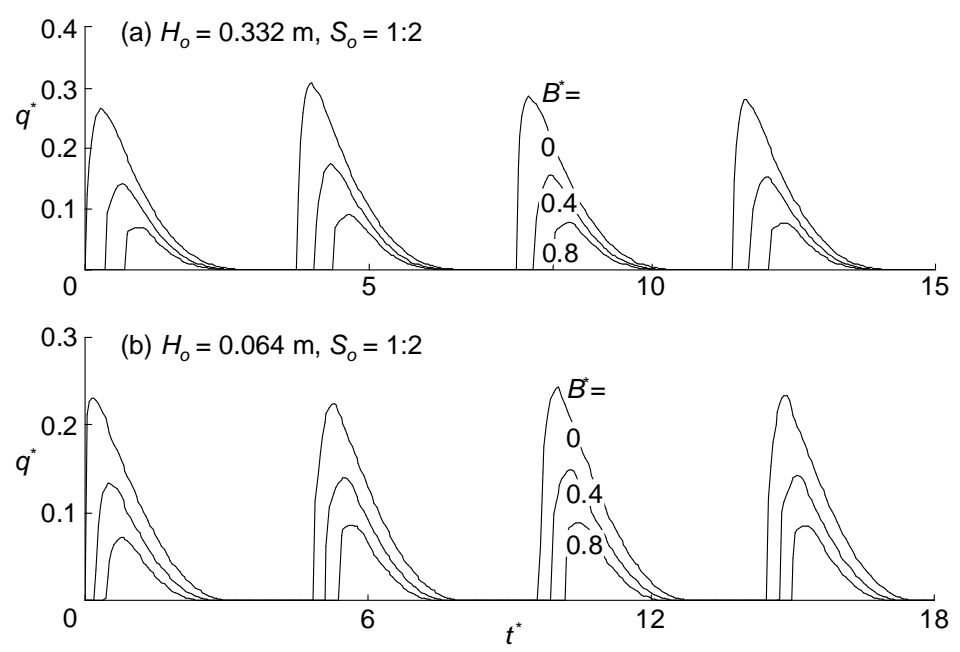

Figure 16. The intermittent overtopping discharge $q^{*}\left(t^{*}\right)$ produced by the periodic waves; (a) $H_{o}=0.332 \mathrm{~m}, S_{0}$ $=1 \mathrm{v}: 2 \mathrm{~h}$, and (b) $H_{o}=0.064 \mathrm{~m}, S_{o}=1 \mathrm{v}: 2 \mathrm{~h}$ for three berm heights $B^{*}=2 B / R_{\max }=0,0.4$ and 0.8 .
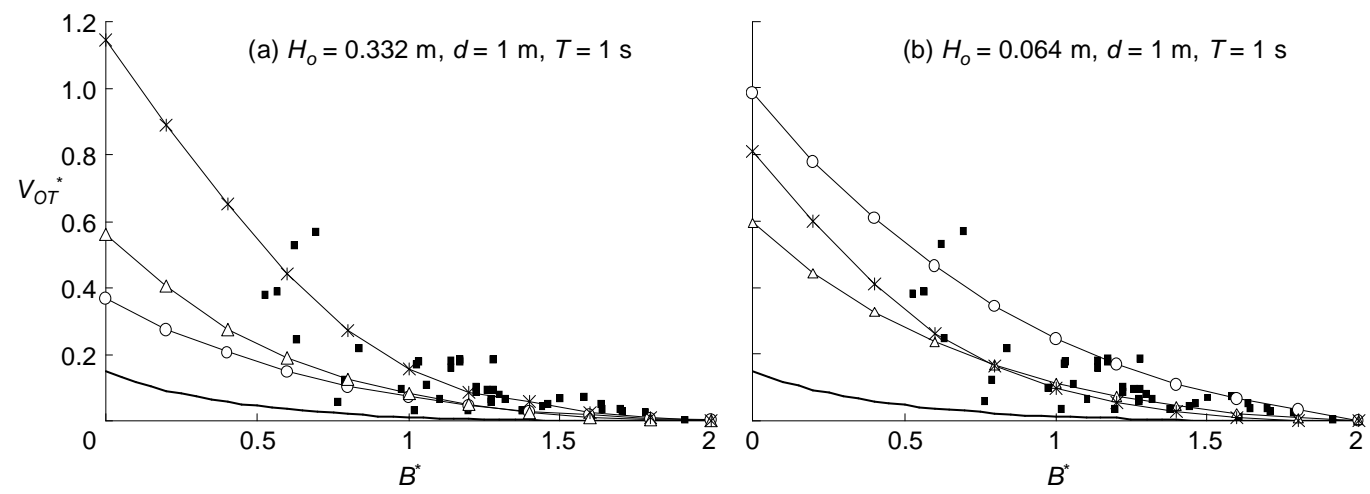

Figure 17. Overtopping volume per wave of two periodic waves (a) $H_{o}=0.332 \mathrm{~m}$ and (b) $\boldsymbol{H}_{o}=0.064 \mathrm{~m}$ on slopes $S_{o}=1 \mathrm{v}: 1 \mathrm{~h}$ (circle), 1v:2h (triangle), and 1v:4h (cross). The formula of Peregrine \& Williams (2001) for the collapsing bore is the thick solid line. The laboratory data of Baldock et al. (2005) for periodic waves is denoted by solid rectangle. 

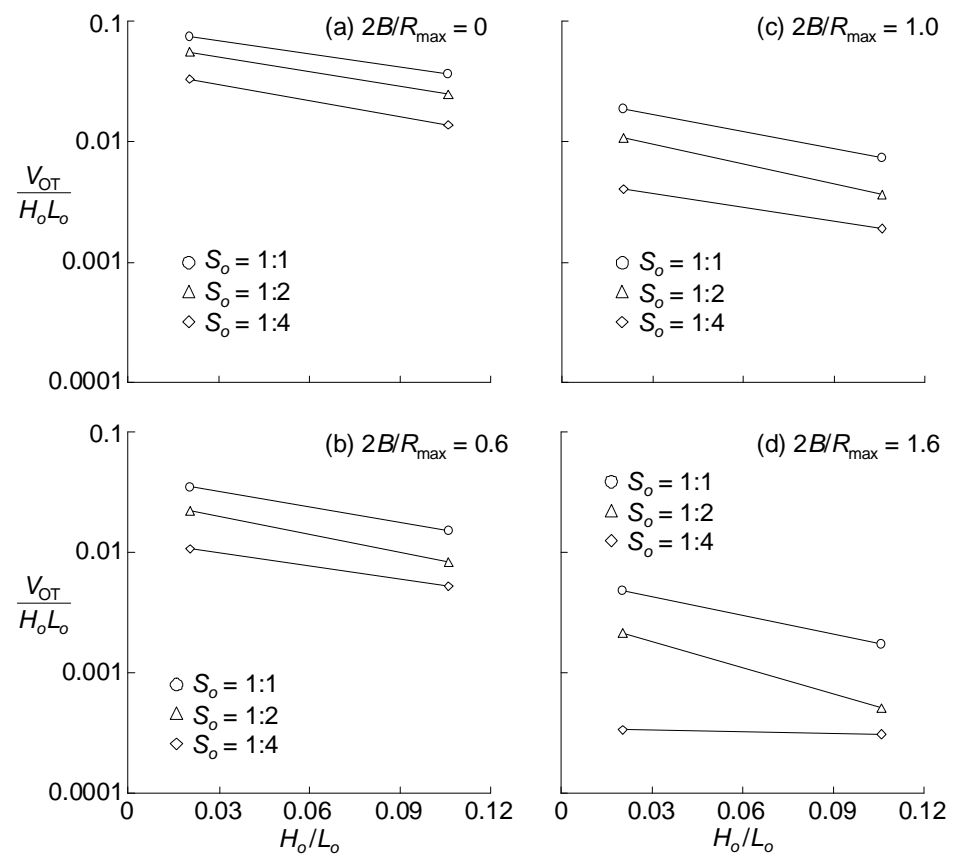

Figure 18. Overtopping volume per wave of the two periodic waves $H_{o}=0.332 \mathrm{~m}$ and $0.064 \mathrm{~m}$ on slopes $S_{o}=$ $1 \mathrm{v}: 1 \mathrm{~h}$ (circle), $1 \mathrm{v}: 2 \mathrm{~h}$ (triangle), and 1v:4h (cross) over berm of height (a) $2 B / R_{\max }=0$, (b) $2 B / R_{\max }=0.6$, (c) $2 B / R_{\max }=1.0$, and (d) $2 B / R_{\max }=1.6$.

\section{CONCLUSION}

This paper takes the advantage of the shock-capturing and shoreline-tracking capabilities of the Lagrangian Block Hydrodynamics (LBH) method to study the periodic waves in the surf zone. The runup and overtopping computations are validated using (i) the exact solutions of Shen \& Meyer (1963) and Peregrine \& Williams (2001) and (ii) the vast amount of laboratory data available for the solitary waves. The results of the runup computations for the periodic waves follow the trend of the formulae recommended for regular (random) waves by the Coastal Engineering Manual (Walton et al. 1989) and the Flood Defense Technical Advisory Committee (van der Meer 2002). The overtopping volumes determined by LBH simulations for the periodic waves fall within the same range as the experimental data of Baldock et al. (2005). The present numerical simulations are the necessary step to take before the ultimate recommendation of the LBH method for coastal engineering design. The inclusion of the sediment suspension and deposition effects in the LBH simulations would be a natural and straightforward extension.

\section{REFERENCES}

Ancey, C., R.M. Iverson, M. Rentschler, and R.P. Denlinger. 2008. An exact solution for ideal dambreak floods on steep slopes. Water Resources Research, 44, W01430-1-10.

Baldock, T.E., M.G. Hughes, K. Day, and J. Louys. 2005. Swash overtopping and sediment overwash on a truncated beach. Coastal Engineering, 52, 633-645.

Battjes, J.A. 1974. Surf similarity. Proceedings of the 14th Coastal Engineering Conference, 1, ASCE, 466-480.

Briganti, R., and N. Dodd. 2009. On the role of shoreline boundary conditions in wave overtopping modelling with non-linear shallow water equations. Coastal Engineering, 56, 1061-1067.

Briggs, M.J., C.E. Synolakis, G.S. Harkins, and S.T. Hughes. 1995. Large scale three-dimensional laboratory measurements of tsunami inundation. In Y. Tsuchiya and N. Shuto (eds,), Tsunami: Progress in Prediction, Disaster Prevention and Warming, 129-149, Kluwer Academic, Netherlands.

Dodd, N. 1998. Numerical model of wave run-up, overtopping, and regeneration. Journal of Waterway, Port, Coastal, and Ocean Engineering, 124(2), 73-81. 
Hall, J.V. and J.W. Watts. 1953. Laboratory investigation of the vertical rise of solitary waves on impermeable slopes. Technical Memo 33, 1-14, Beach Erosion Board, U.S. Army Corps of Engineers.

Hogg, A.J. 2006. Lock-release gravity currents and dam-break flows. Journal of Fluid Mechanics, 569(1), 61-87.

Hsiao, S.-C., T.-W. Hsu, T.-C. Lin, and Y.-H. Chang. 2008. On the evolution and run-up of breaking solitary waves on a mild sloping beach. Coastal Engineering, 55, 975-988.

Hunt, I.A. 1959. Design of seawalls and breakwaters. Journal of the Waterways and Harbors Division, 85(WW3), 123-152.

Jensen A., G.K. Pedersen, and D.J. Wood. 2003. An experimental study of wave run-up at a steep beach. Journal of Fluid Mechanics, 486, 161-188.

Keller, J.B. 1961. Tsunamis - water waves produced by earthquakes. Proceedings of the Tsunami Meetings Associated with the 10th Pacific Science Congress, International Union of Geodesy and Geophysics, 154-166.

Kobayashi, N., and A. Wurjanto. 1989. Wave overtopping on coastal structures. Journal of Waterway, Port, Coastal, and Ocean Engineering, 115(2), 235-251.

Li, Y., and F. Raichlen. 2002. Non-breaking and breaking solitary wave run-up. Journal of Fluid Mechanics, 456, 295-318.

Lynett, P. and P.L.-F. Liu. 2002. Modeling wave runup with depth-integrated equations. Coastal Engineering, 46, 89-107.

Miche, M. 1951. Le pouvoir réfléchissant des ouvrages maritimes exposés à l'action de la houle. Annals des Ponts et Chaussess, 121e Annee, 285-319 [translated by Lincoln and Chevron, 1954. University of California, Berkeley, Wave Research Laboratory, 3(363)].

Peregrine, D.H., and S.M. Williams. 2001. Swash overtopping a truncated plane beach. Journal of Fluid Mechanics, 440, 391-399.

Ritter, A. 1892. Die fortpflanzung der wasserwellen (The propagation of water waves). Zeitschrift des Vereines Deutscher Ingenieure, 36(33), 947-954 [in German].

Shen, M.C., and R.E. Meyer. 1963. Climb of a bore on a beach 3: Run-up. Journal of Fluid Mechanics, $16,113-125$.

Shore Protection Manual. 1984. U.S. Army Engineer Waterways Experiment Station, 4th edn., US Government Printing Office, Washington, D.C.

Stoker, J.J. 1957. Water Waves: The Mathematical Theory with Applications. Wiley Interscience, New York.

Synolakis, C.E. 1986. The runup of solitary wave. $\mathrm{PhD}$ thesis, California Institute of Technology, Pasadena, CA.

Tan, L.-W. and V.H. Chu. 2009a. Lauber and Hager's dam-break wave data for numerical model validation. Journal of Hydraulic Research, 47(4), 524-528.

Tan, L.-W. and V.H. Chu. 2009b. Simulation of wave fronts on dry beds using Lagrangian blocks. Engineering and Computational Mechanics, 162(EM2), 57-66.

Tan, L.-W. and V.H. Chu. 2010a. Wave runup simulations using Lagrangian blocks on Eulerian mesh. J. Hydro-Environ. Res., 3(4), pp. 193-200.

Tan, L.-W. and V.H. Chu. 2010b. Wet-and-dry interface on steep slopes simulations using Lagrangian blocks. Environmental Hydraulics, CRC Press/Balkema (ISBN 978-0-415-58475-3), Vol. 2, pp. 997-102

Tan, L.-W. and V.H. Chu. 2010c. Dam-break flood simulations using 2D Lagrangian blocks on Eulerian mesh method. Environmental Hydraulics, CRC Press/Balkema (ISBN 978-0-41558475-3), Vol. 2, pp. 1003-1008.

Thacker, W.C. 1981. Some exact solutions to the nonlinear shallow-water wave equations. Journal of Fluid Mechanics, 107, 499-508.

Titov, V.V., and C.E. Synolakis. 1995. Modeling of breaking and non-breaking long-wave evolution and run-up using VTCS-2. Journal of Waterway, Port, Coastal, and Ocean Engineering, 121, 308-461.

van der Meer, J.W. 2002. Technical report on wave run-up and wave overtopping at dikes. Report of $T A W$, Technical Advisory Committee for Flood Defence in the Netherlands (TAW), Delft.

Walton, T.L., Jr., J.P. Ahrens, C.L. Truitt, and R.G. Dean. 1989. Criteria for evaluating coastal floodprotection structures. Technical Report CERC-89-15, U.S. Army Engineer Waterways Experiment Station, Coastal Engineering Research Center, Vicksburg, MS. 